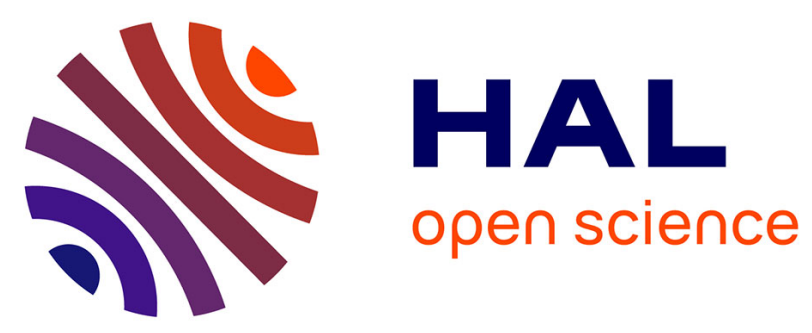

\title{
Capillary electrophoresis with electrospray ionisation-mass spectrometry for the characterisation of degradation products in aged papers
}

\author{
Anne-Laurence Dupont, Agathe Seemann, Bertrand Lavédrine
}

\section{- To cite this version: \\ Anne-Laurence Dupont, Agathe Seemann, Bertrand Lavédrine. Capillary electrophoresis with electro- spray ionisation-mass spectrometry for the characterisation of degradation products in aged papers. Talanta, 2012, 89, pp.301-309. 10.1016/j.talanta.2011.12.032 . hal-01491170}

\author{
HAL Id: hal-01491170 \\ https://hal.science/hal-01491170
}

Submitted on 22 Mar 2017

HAL is a multi-disciplinary open access archive for the deposit and dissemination of scientific research documents, whether they are published or not. The documents may come from teaching and research institutions in France or abroad, or from public or private research centers.
L'archive ouverte pluridisciplinaire HAL, est destinée au dépôt et à la diffusion de documents scientifiques de niveau recherche, publiés ou non, émanant des établissements d'enseignement et de recherche français ou étrangers, des laboratoires publics ou privés. 


\title{
Capillary electrophoresis with electrospray ionisation-mass spectrometry for the characterisation of degradation products in aged papers
}

\author{
Anne-Laurence Dupont*, Agathe Seemann, Bertrand Lavédrine \\ Centre de recherche sur la conservation des collections, Muséum national d'Histoire naturelle, CNRS USR 3224, 36 rue Geoffroy-Saint-Hilaire, F-75005 Paris, France
}

\section{A R T I C L E I N F O}

\section{Article history:}

Received 1 September 2011

Received in revised form

29 November 2011

Accepted 4 December 2011

Available online 19 December 2011

\section{Keywords:}

Capillary electrophoresis

Electrospray ionisation

Mass spectrometry

Cellulose

Artificial ageing

Degradation

\begin{abstract}
A B S T R A C T
A methodology for capillary electrophoresis/electrospray ionisation mass spectrometry (CE/ESI-MS) was developed for the simultaneous analysis of degradation products from paper among two families of compounds: low molar mass aliphatic organic acids, and aromatic (phenolic and furanic) compounds. The work comprises the optimisation of the CE separation and the ESI-MS parameters for improved sensitivity with model compounds using two successive designs of experiments. The method was applied to the analysis of lignocellulosic paper at different stages of accelerated hygrothermal ageing. The compounds of interest were identified. Most of them could be quantified and several additional analytes were separated.
\end{abstract}

(C) 2011 Elsevier B.V. All rights reserved.

\section{Introduction}

The study of by-products from paper degradation formed during natural and artificial ageing is essential for the understanding of the deterioration of cellulosic materials, and is a fundamental area of research in the field of preservation of paper-based cultural heritage objects. For a fine physico-chemical characterisation of the degradation of cellulosics, sensitive analytical methods have to be developed to enable the possible diagnostics of the alteration levels with application to historic objects. The aim of characterising degradation products from paper is thereby also to identify molecular markers of this degradation and is anticipated as a means to understand the alteration pathways. Due to sampling constraints, a primary aim in the field of cultural heritage preservation science is to establish useful micro-destructive, and whenever possible, noninvasive methodologies. If often material sampling is unavoidable, these techniques should evolve towards sample miniaturisation and reduced solvent consumption. In that respect, capillary electrophoresis (CE) is a technique of choice, well adapted to minute amounts of sample. The performance of this technique in terms of selectivity, efficiency and resolving power is even enhanced when coupled to high sensitivity detectors such as mass spectrometers (MS). Several methods using CE and UV detection with a photodi-

\footnotetext{
* Corresponding author. Tel.: +33 14079 5307; fax: +33 140795312.

E-mail address: aldupont@mnhn.fr (A.-L. Dupont).
}

ode array (PDA) have been proposed for the analysis of papers from naturally aged books as well as for model papers in a previous publication by the authors [1]. In that work, compounds formed during holocellulose and lignocellulose degradation such as carbohydrates (mono-, di-, and oligosaccharides), low molar mass organic acids (LMMOA), and aromatic (phenolic and furanic) compounds were identified and quantified in aqueous extracts from papers. Among these, a few were proposed as possible molecular indicators of historic papers alteration. A good performance in terms of accuracy, precision and sensitivity of these methods was shown. However, the methods have their shortcomings. UV detection, which is the most commonly used detection mode in $\mathrm{CE}$, requires dedicating a specific method to each family of compound depending on their UV-absorbing characteristics. For instance, whereas aromatic compounds absorb in UV, simple aliphatic organic acids do not. As for carbohydrates, they need to be derivatised in order to be UV-absorbent in a more practical wavelength range and ionisable at lower $\mathrm{pH}$. Moreover, different buffers and run conditions are required. As a result, from sample preparation to analysis, the identification of the various families of compounds cannot be carried out simultaneously. The analyses are thus rather time-consuming and work-intensive. Additionally, as it is based exclusively on migration time $\left(t_{\mathrm{m}}\right)$ and UV spectra profiles, the identification in CE/UV is entirely dependent upon the availability of molecular standards. In our previous work, the model compounds chosen to serve as standards were selected based on notorious degradation products from cellulose, hemicelluloses, and lignin [2-6]. While the majority 
Table 1

Chemical structure, $\mathrm{p} K_{\mathrm{a}}$, molar mass $(\mathrm{Mr})$ and $m / z$ of the standard compounds, average migration time and repeatability $(r)$ on $t_{\mathrm{m}}(\mathrm{RSD} \%)(n=6)$.

\begin{tabular}{|c|c|c|c|c|c|c|}
\hline Compound & Structure & $\mathrm{p} K_{\mathrm{a}}$ & $\operatorname{Mr}\left(\mathrm{g} \mathrm{mol}^{-1}\right)$ & $m / z[\mathrm{M}-\mathrm{H}]^{-}$ & $t_{\mathrm{m}}(\min )$ & $r(\mathrm{RSD} \%)$ \\
\hline Lactic acid & & 3.9 & 90 & 89 & 7.65 & 2.4 \\
\hline Glycolic acid & & 3.83 & 76 & 75 & 8.48 & 2.4 \\
\hline Succinic acid & 0 & $\begin{array}{l}4.21 \\
5.64\end{array}$ & 118 & 117 & 12.09 & 1.7 \\
\hline Acetosyringone & & 7.88 & 196 & 195 & 6.03 & 1.3 \\
\hline 4-Hydroxyacetophenone & & 8.05 & 136 & 135 & 6.25 & 1.6 \\
\hline 4-Hydroxybenzaldehyde & & 7.72 & 122 & 121 & 6.80 & 1.8 \\
\hline 2-Furoic acid & & 3.16 & 112 & 111 & 7.51 & 2.3 \\
\hline Vanillic acid & & 4.31 & 168 & 167 & 7.00 & 2.1 \\
\hline Vanillin & & 7.38 & 152 & 151 & 6.60 & 1.8 \\
\hline
\end{tabular}

of the peaks present on the electropherograms could be identified, a few remained unidentified.

The use of mass spectrometry, a more universal detection mode, replaces favourably UV detection by providing some structural and molar mass $(\mathrm{m} / \mathrm{z}$ ) information. Moreover, CE/MS is extremely selective, which compensates for slight variations in $t_{\mathrm{m}}$ of the analytes, and allows discriminating between co-eluting molecules of different nominal masses by extracting particular $m / z$ from the total ion electropherograms (TIE). In the case of the electrospray ionisation (ESI) source and the ion trap analyser (IT) it is even possible to distinguish compounds with same $m / z$ and same $t_{\mathrm{m}}$ through ion fragmentation (MS/MS). Several review articles of CE/MS and the multiple applications that have been developed in the past 20 years that the technique has been in use have been published recently, especially in the field of bioanalysis [7-9]. CE/ESI-MS in particular is foreseen as the preferred tool for the analysis of complex biological samples and forensic samples $[10,11]$. In the present work,
CE/ESI-MS was explored for the simultaneous analysis of degradation by-products from paper among two families of compounds mentioned above, namely LMMOA and aromatic compounds. To this end, an ion trap mass spectrometer (IT-MS) with ESI source was used. The method was first developed using molecular standards, and was then applied to real paper samples which had undergone several stages of artificial ageing.

\section{Experimental}

\subsection{Sample preparation}

A paper made of groundwood pulp (75\%) and softwood cellulose chemical pulp (25\%), henceforth denoted P3, was used. Its basis weight is $80 \mathrm{~g} \mathrm{~m}^{-2}$ and it has a cold extract pH of 5.4 (TAPPI T509 om-02). According to the manufacturer P3 is sized with alum/rosin 
and contains $20 \%$ of kaolin filler. This paper was especially produced industrially in 1990 for the European project STEP. The artificial ageing was carried as follows: sets of $4 \mathrm{~g}$ of P3 preconditioned to $23^{\circ} \mathrm{C}$ and $50 \% \mathrm{rH}$ were inserted inside $144 \mathrm{~mL}$ glass tubes (Alltech Associates) which were hermetically sealed and placed in a dry heat oven (Memmert) at $100^{\circ} \mathrm{C}$, during 5 and 14 days, following the ASTM standard D6819-02e2. This accelerated ageing method has been proposed to better represent natural ageing than hygrothermal ageing in hanging sheets configuration in a climatic chamber (controlled temperature and relative humidity $(\mathrm{rH}))[6,12-14]$. During the ageing, the humidity in the tube is supplied and buffered by the paper, and stabilises at about $50-60 \% \mathrm{rH}$ [13]. After ageing, paper samples (900 $\mathrm{mg}$ ) were cut in $2 \mathrm{~mm}^{2}$ pieces and were immersed in $4 \mathrm{~mL}$ Ultrapure deionised water (Millipore) at room temperature for $3 \mathrm{~h}$. The water extract was filtered on a PTFE $0.45 \mu \mathrm{m}$ pores membrane for analysis. The extraction procedure had been optimised upon various tests of analytes recovery based upon previous work $[1,6]$.

\subsection{Chemicals}

The chemicals used were the following: glycolic acid (99\%, Merck), lactic acid (85+\% soln. in water, Sigma-Aldrich), succinic acid (>99.5\%, Fluka), 3,5-dimethoxy-4-hydroxyacetophenone (acetosyringone) (97\%, Aldrich), 4-hydroxyacetophenone (99\%, Aldrich), 4-hydroxy-3-methoxybenzaldehyde (vanillin) ( $\geq 98 \%$ Fluka), 4-hydroxybenzaldehyde (98\%, Aldrich), 4hydroxy-3-methoxybenzoic acid (vanillic acid) ( $\geq 98 \%$, Merck), 2-furancarboxylic acid (2-furoic acid) (98\%, Aldrich), ammonium acetate ( $\geq 99 \%$, Fluka), ammonium formate ( $\geq 99 \%$, Fluka), ammonium hydroxide ( $\mathrm{N} 28 \%$ in $\mathrm{H}_{2} \mathrm{O}$, Fluka), methanol (HPLC grade, Merck), formic acid (96\%, Sigma-Aldrich). The chemical structure of the standard molecules used can be found in Table 1 .

\subsection{CE/ESI-MS}

Electrophoretic separations were performed with a P/ACE MDQ capillary electrophoresis instrument (Beckman Coulter). The system operation and data acquisition were performed using 32 Karat 5.0 software (Beckman Coulter). A mass spectrometer HCT-Ultra (Brucker Daltonics) was used with an ion trap analyser equipped with an electrospray ionisation source. The detection mass range is $50-3000 \mathrm{~m} / \mathrm{z}$ in standard mode and $200-6000 \mathrm{~m} / \mathrm{z}$ in extended mode. The software package Compass 1.3 for Esquire/HCT was used for data acquisition and analysis. CE/MS coupling was carried out using a sheath liquid coaxial interface (Agilent Technologies). The central needle of the interface, in which the CE capillary is inserted, is surrounded by a middle capillary through which the sheath liquid flows; the outer capillary channels the nebulising gas $\left(\mathrm{N}_{2}\right)$.

For CE, a bare fused silica capillary of $50 \mu \mathrm{m}$ internal diameter (ID) (Beckman Coulter) and $63 \mathrm{~cm}$ length was used. Prior to injection the capillary was rinsed by flushing $2 \mathrm{~min}$ with deionised water, followed by conditioning for $5 \mathrm{~min}$ with the background electrolyte (BGE). The BGE was ammonium formate $20 \mathrm{mM}$ at $\mathrm{pH}$ 9 or $\mathrm{pH} 10$ (adjusted with $\mathrm{NH}_{4} \mathrm{OH} 1 \mathrm{M}$ ). The injection was made in hydrodynamic mode by applying a pressure of $0.6 \mathrm{psi}$ for $3.5 \mathrm{~s}$. A separation voltage of $+20 \mathrm{kV}$ was progressively applied to the anodic end with a ramp time of $1 \mathrm{~min}$. The resulting current was stable, between -15 and $-16 \mu \mathrm{A}$. The run temperature was fixed to $25^{\circ} \mathrm{C}$. After each analysis the capillary was rinsed for 2 min with deionised water. All cleaning steps were pressure-driven and carried at 20 psi.

For ESI-MS, the negative ion mode was used over the scan range from 50 to $250 \mathrm{~m} / \mathrm{z}$ with a target mass set to $\mathrm{m} / \mathrm{z} 100$ (detected ions are $[\mathrm{M}-\mathrm{H}]^{-}$). The following MS parameters were used: capillary voltage of $+4000 \mathrm{~V}$, end plate offset of $-500 \mathrm{~V}$ and skimmer
Table 2

Levels for the optimised experimental parameters: \% $\mathrm{MeOH}$ in the sheath liquid $(M)$, sheath liquid flow rate $(L)$ and nebulising gas pressure $(N)$.

\begin{tabular}{lccccc}
\hline & Level -1.63 & Level -1 & Level 0 & Level +1 & Level +1.63 \\
\hline$M(\%)$ & 27 & 40 & 60 & 80 & 92 \\
$L\left(\mu \mathrm{Lh}^{-1}\right)$ & 168 & 200 & 250 & 300 & 331 \\
$N(\mathrm{psi})$ & 2 & 5 & 10 & 15 & 18 \\
\hline
\end{tabular}

voltage of $-40 \mathrm{~V}$. The maximum accumulation time was $100.00 \mathrm{~ms}$ and the smart target (maximum number of ions in the trap) was set to 90,000 , using an average of 5. The optimal protruding length of the CE capillary from the interface, which is reported to influence the quality of the spray [15], was about $0.2-0.3 \mathrm{~mm}$. The mass spectra were acquired in standard enhanced resolution mode (scan speed $8100 \mathrm{~m} / \mathrm{zs}^{-1}$, resolution 0.4 FWHM (Full-Width at Half-Maximum $/ \mathrm{m} / \mathrm{z}$ ). In the optimised method, the sheath liquid consisted of methanol/water $(80: 20, v / v)$ with $0.1 \%$ of formic acid, and was co-injected with a syringe pump at a flow rate of $300 \mu \mathrm{Lh}^{-1}$. The nebulising gas $\left(\mathrm{N}_{2}\right)$ pressure was set to $15 \mathrm{psi}$. The drying gas temperature was $200^{\circ} \mathrm{C}$ and its flow rate was $6 \mathrm{~L} \mathrm{~min}^{-1}$.

\subsubsection{Optimisation of the CE separation}

The optimisation of the CE conditions was dedicated to finding optimal $\mathrm{pH}$ and concentration (ionic strength) of the BGE. Stock solutions were made up with the LMMOA only or with the nine model analytes (3 LMMOA and 6 aromatic derivatives) (Table 1) at a concentration of $20 \mathrm{ppm}$ each in water or methanol/water $\left(\mathrm{MeOH} / \mathrm{H}_{2} \mathrm{O}\right)$ (50:50). All ESI and MS parameters were as described above.

\subsubsection{Optimisation of ESI parameters}

In order to determine the parameters that most influence the intensity of the detection signal, a two-level fractional factorial design was first applied for broad screening [16]. The design consisted of 8 analysis runs with different settings combinations of 6 factors at low $(-1)$ or high $(+1)$ level. These factors were: flow rate, methanol and formic acid content of the sheath liquid, nebulising gas pressure, and temperature and flow rate of the drying gas (see Table S1 in the supplementary material). The IT detection parameters (ion mode, applied voltage) were constant, and the CE electrolyte was ammonium formate $20 \mathrm{mM} \mathrm{pH} 10$. The injected sample was the stock solution of the three LMMOA in $\mathrm{H}_{2} \mathrm{O}$. The sum of the peak heights of the 3 compounds was used as output response.

In a second step the parameters which stood as the most influential were optimised by applying a central composite design (CCD) which consisted of 12 analyses runs carried out in randomised order. The CE electrolyte was ammonium formate $20 \mathrm{mM} \mathrm{pH} 10$. The injected sample was the stock solution of the 9 model compounds in $\mathrm{MeOH} / \mathrm{H}_{2} \mathrm{O}(50 / 50)$. The factors of the CCD are listed in Table 2 as well as their levels $(-\alpha,-1,0,+1,+\alpha)$. The data treatment was carried out independently for each compound considering the response of both $\mathrm{S} / \mathrm{N}^{\prime}$ (signal-to-noise ratio) and peak height on the extracted ion electropherograms (EIE). A linear polynomial model was used to fit the experimental results.

\section{Results and discussion}

\subsection{Optimisation of the CE separation}

ESI, also called sheath flow interface, is the preferred interface for $\mathrm{CE} / \mathrm{MS}$ as it allows molecules to be transferred directly from the liquid phase to the gas phase. Volatile buffers with low salt concentrations are thus needed, which excludes a number of buffers among those most commonly used in CE/UV. Ammonium acetate 
and ammonium formate buffers are preferred, and have been successfully applied in CE/ESI-MS for the analysis of natural products such as substituted phenols and aromatic acids from biomass [17], phenolic compounds in food matrices such as walnut [18] and olive oil [19,20], bacterial LMM carboxylic acids metabolites [21,22], LMM carboxylic acids in fruit juice [23], and functionalised and long chain carboxylic acids in atmospheric particles and cloud water [16]. Electroosmotic flow (EOF) modifiers are rarely used but DETA (diethylenetriamine), for instance, has been reported in CE/ESI-MS of LMMOA [24]. The simple reversal of the charge on the silica wall of the capillary enabling reverse mode CE by adding-in the buffer surfactants commonly used in CE/UV such as cetyltrimethylammonium bromide [25], allows for a faster separation of small anions such as the LMMOA. However surfactants are notorious to cause ion suppression and disturb the MS measurement [26].

The aim of this work was to achieve the separation of paper degradation compounds, namely LMMOA and aromatic lignin derivatives, in a single run. Together with our parallel study on (hemi)cellulose and lignin degradation products in pulp bleaching effluents and naturally aged book [27], this is, to our knowledge, the first attempt to date to simultaneously determine these two types of compounds in one analysis. The option of wall coating one way or another $[21,28,29]$ was excluded as it would have likely optimised the separation of LMMOA at the expense of lignin derivatives. An ammonium acetate buffer was first tried but resulted not fully satisfactory as the acetate ion $(\mathrm{m} / z 59)$ produced high background intensity on the TIE and noise on the spectra. Ammonium formate resulted in better quality TIE, the background noise being much reduced as the $m / z$ of formate is below the detection level ( $m / z 45)$.

\subsubsection{BGE's $p H$}

The effect of $\mathrm{pH}$ was studied first as it can affect both the mobility of the analytes and the EOF. The standard compounds used for the method development have $\mathrm{p} K_{\mathrm{a}}$ values between 3.16 and 8.05 (Table 1). In order for all the analytes to be deprotonated and bear a negative charge, the $\mathrm{pH}$ of the background electrolyte (BGE) should consequently be above 8 . The EOF being directed towards the cathode, all the analytes will migrate counter flow, slower than the EOF. The useful $\mathrm{pH}$ range being thus quite restricted, ammonium formate $20 \mathrm{mM}$ buffer was tested at pH 9 and 10. The EOF resulted not significantly different as above $\mathrm{pH} 8$ the silica is fully negatively charged, and at $\mathrm{pH} \geq 9$ it reaches its maximum value. The migration time of the analytes was globally consistent with their $\mathrm{m} / \mathrm{z}$ ratio, the heavier carbonyl functionalised phenols having shorter $t_{\mathrm{m}}$, and the LMMOA longer $t_{\mathrm{m}}$, with the doubly charged succinic acid being the slowest migrating species (Fig. 1). At pH 10, all the analytes migrated within 8.5 min, but vanillin and 4-hydroxyacetophenone were not optimally resolved $\left(R_{\mathrm{S}}=0.38\right)$. The resolution of band pairs was calculated as $R_{\mathrm{s}}=1.177\left(t_{\mathrm{m} 2}-t_{\mathrm{m} 1}\right) /\left(W_{0.5,1}+W_{0.5,2}\right)$, where $t_{\mathrm{m} 1}$ and $t_{\mathrm{m} 2}$ are the migration times of the first and second adjacent bands and $W_{0.5,1}$ and $W_{0.5,2}$ their bandwidth at half height [30]. At $\mathrm{pH} 9$, the analysis was completed within $12 \mathrm{~min}$ and the lowest $R_{\mathrm{S}}(0.94)$ achieved was for the band pair vanillic acid/2-furoic acid. For all other band pairs, resolutions values above 1.6 were obtained (Fig. 2b). As the sensitivity of the detection was similar at $\mathrm{pH} 9$ and 10 , the two buffers have been used in the following.

\subsubsection{BGE's concentration}

Usually lower ionic strength buffers are preferred, because they allow faster separations and because they interfere less with the ionisation of the analytes. The concentrations of ammonium formate tested were 10,20 and $40 \mathrm{mM}$, at $\mathrm{pH} 9$. As expected, at high ionic strength, with a slower EOF, the analytes' $t_{\mathrm{m}}$ increased (Fig. 2a). This influenced the resolution accordingly, the best separation being achieved with the $40 \mathrm{mM}$ buffer (Fig. 3). For instance, while at $10 \mathrm{mM}, R_{\mathrm{S}}$ was as low as 0.14 for the pair acetosyringone/
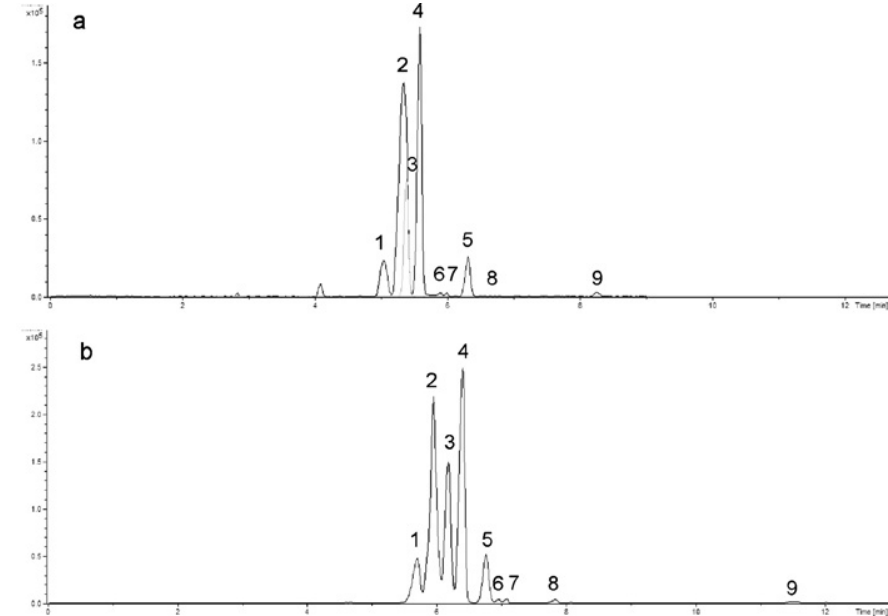

Fig. 1. BPE of the standards mixture, $20 \mathrm{ppm}$ each, separation voltage $20 \mathrm{kV}$, hydrodynamic injection $0.6 \mathrm{psi}$ during $3.5 \mathrm{~s}$. (a) Electrolyte: ammonium formate $20 \mathrm{mM}$ pH 10, (b) electrolyte: ammonium formate $20 \mathrm{mM} \mathrm{pH} \mathrm{9,} \mathrm{with} \mathrm{(1)} \mathrm{acetosyringone,} \mathrm{(2)}$ 4-hydroxyacetophenone, (3) vanillin, (4) 4-hydroxybenzaldehyde, (5) vanillic acid, (6) 2-furoic acid, (7) lactic acid, (8) glycolic acid, (9) succinic acid.
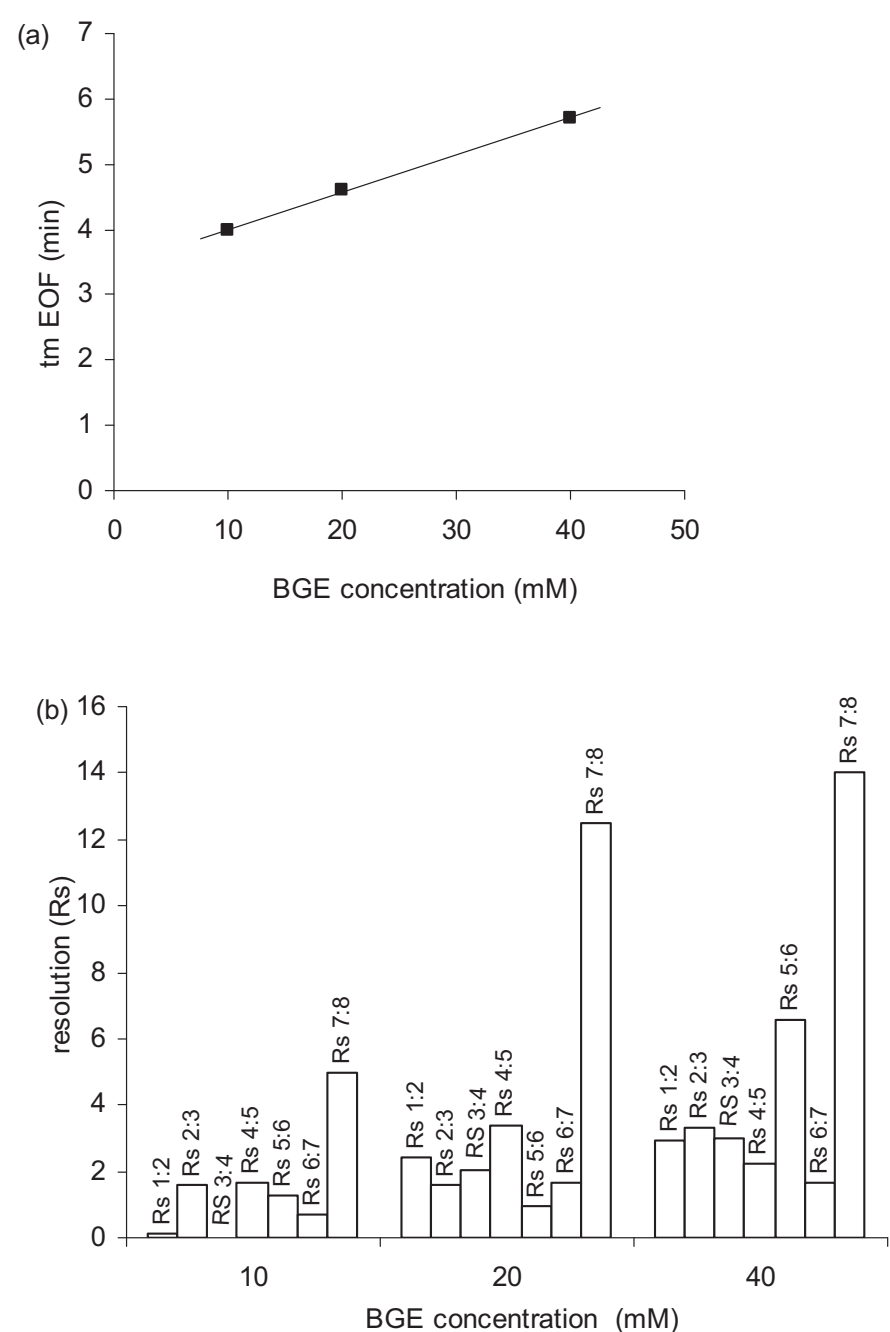

Fig. 2. (a) EOF as a function of BGE concentration (ammonium formate pH9), (b) resolution $\left(R_{\mathrm{s}}\right)$ of band pairs on the TIE with ammonium formate $20 \mathrm{mM}$ $\mathrm{pH}$ 9: (1) acetosyringone, (2) 4-hydroxyacetophenone, (3) vanillin, (4) 4 hydroxybenzaldehyde, (5) vanillic acid, (6) 2-furoic acid, (7) lactic acid, (8) glycolic acid. 


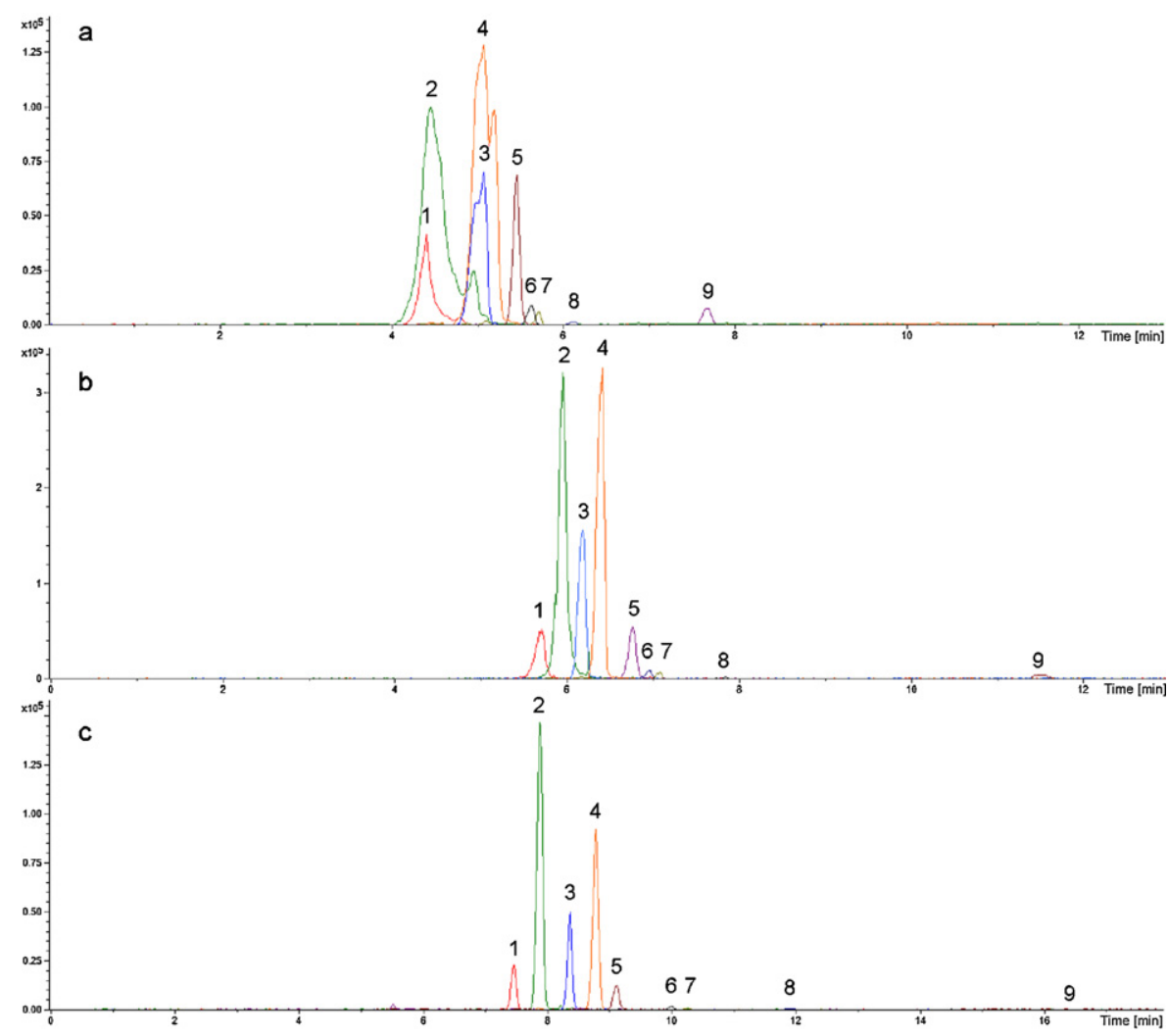

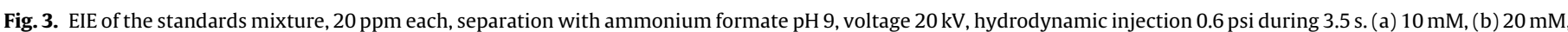

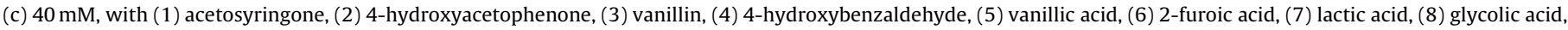
(9) succinic acid.

4-hydroxyacetophenone and 0.72 for 2 -furoic acid/lactic acid, it was 2.9 and 1.6 at $40 \mathrm{mM}$, respectively (Fig. 2b). However, the sensitivity of the detection was lower at $40 \mathrm{mM}$ due to the high amount of buffer ions $v$ s. analyte ions entering the ion trap, which often results in suppression of ionisation and high background noise [31,32]. The best compromise between resolution and detection sensitivity was obtained with ammonium formate $20 \mathrm{mM}$ (Fig. 3b).

\subsection{Optimisation of the ESI-MS parameters}

Sensitivity of the MS detection is highly dependent on several parameters related to the interface such as sheath liquid, nebulising gas, drying gas and protruding length of the CE capillary from the injection sprayer [15,33,34]. In order to fully optimise these ESI parameters in fewer experimental steps, two successive designs of experiments (DOE) were applied. In the first DOE, 6 factors were tested for their influence on the sensitivity of the signal. Table S1 (supplementary material) shows the results of this screening with the levels chosen for each experimental parameter and the coefficients calculated which, neglecting the interaction terms between the factors, and using the sum of the intensity of the peaks as output response, fitted a linear model. The parameters found to have the highest influence on the sensitivity of the detection, i.e. those with largest coefficients (absolute values), were the sheath liquid flow rate, its $\mathrm{MeOH}$ content, and the nebulising gas pressure. Both the percentage of $\mathrm{MeOH}$ in the sheath liquid and the nebulising gas pressure had positive coefficients, i.e. higher values thereof led to higher signal intensity. Conversely, the sheath liquid flow rate had a negative coefficient indicating that a higher value led to lower signal intensity. These findings are partly in contrast with published results where the sheath liquid flow rate had only a minor impact [16]. However, they can be accounted for, considering that with a good ionisation output, higher flow rates dilute the analytes to a larger extent. The remaining three factors did not strongly influence the peak intensity within the tested range. Not unexpectedly, the concentration of formic acid in the sheath liquid had a negligible influence, the analytes being ionised when reaching the ESI interface. The drying gas's role also resulted in being peripheral as reported by other authors [33].

Only the three most important parameters determined previously were used to further refine the optimisation of the methodology with a central composite design (CDD) (Table 2). The values of the remaining three factors were set arbitrarily, with a concentration of formic acid in the sheath liquid of $0.1 \%$, and for the drying gas, a temperature of $200^{\circ} \mathrm{C}$ and a flow rate of $6 \mathrm{~L} \mathrm{~min}^{-1}$.

A linear model using as variables each parameter and interactions between each couple thereof was postulated as follows:

$Y=a+b M+c L+d N+e M L+f M N+g L N$

with $a, b, c, d, e, f$ and $g$, the coefficients to be determined by the model; $M$, the percentage of $\mathrm{MeOH}$; the sheath liquid flow rate and $N$, the pressure of the nebulising gas.

Table S2, in the supplementary material, shows the linear equations obtained for each model compound, which allowed the calculation of the theoretical response for each combination of parameters. The difference between the theoretical (predicted) values and the measured (residual) values allowed the determination of the uncertainty level of the model. This difference was smaller than the standard deviation of the measurement calculated on 4 non-consecutive runs for all the analytes, which confirmed that the linear model was indeed appropriate to describe the system 
Table 3

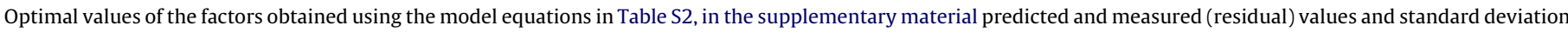
(SD) calculated on 4 non-consecutive runs for $\mathrm{S} / \mathrm{N}^{\prime}$ and signal intensity.

\begin{tabular}{|c|c|c|c|c|c|c|c|c|c|c|c|}
\hline & \multicolumn{3}{|c|}{ Optimised exp. factors } & \multicolumn{4}{|l|}{$\mathrm{S} / \mathrm{N}^{\prime}$} & \multicolumn{4}{|c|}{ Signal intensity (counts) } \\
\hline & $M$ & $L$ & $N$ & Predicted $(P)$ & Residual $(R)$ & $(R-P)$ & $\mathrm{SD}(n=4)$ & Predicted $(P)$ & Residual $(R)$ & $(R-P)$ & $\mathrm{SD}(n=4)$ \\
\hline Lactic acid & 80 & 300 & 15 & 11.7 & 11.9 & 0.2 & 2.1 & 7796 & 7273 & -523 & 1403 \\
\hline Glycolic acid & 80 & 300 & 15 & 23.2 & 23.9 & 0.7 & 2.7 & 1765 & 1701 & -64 & 135 \\
\hline Succinic acid & 80 & 300 & 15 & 50.4 & 53 & 2.6 & 13.1 & 8926 & 9141 & 215 & 2538 \\
\hline Acetosyringone & 80 & 300 & 15 & 91.3 & 81.9 & -9.4 & 12.3 & 25,396 & 24,344 & -1052 & 4129 \\
\hline 4-Hydroxyacetophenone & 80 & 300 & 15 & 268.9 & 280.7 & 11.8 & 46.9 & 179,931 & 177,077 & -2854 & 31,505 \\
\hline 4-Hydroxybenzaldehyde & 80 & 300 & 15 & 412.8 & 407.9 & -4.9 & 91.4 & 318,679 & 315,069 & -3610 & 47,180 \\
\hline 2-Furoic acid & 80 & 300 & 15 & 63.8 & 66.2 & 2.4 & 11.1 & 9354 & 9721 & 367 & 1529 \\
\hline Vanillic acid & 80 & 300 & 15 & 102.2 & 108.7 & 6.5 & 10.6 & 24,340 & 24,188 & -152 & 1936 \\
\hline Vanillin & 80 & 300 & 15 & 201.7 & 208.6 & 6.9 & 53.4 & 96,018 & 95,179 & -839 & 27,278 \\
\hline
\end{tabular}

(Table 3). In order to maximise the MS signal, the parameters values were further optimised using Excel software, by restraining the variables to the studied domain. It was found that the optimal parameters defined through the CDD were: a flow rate of $300 \mu \mathrm{Lh}^{-1}$, the percentage of $\mathrm{MeOH}$ of $80 \%$ for the sheath liquid, and the pressure of 15 psi for the nebulising gas. High nebulising gas pressure and high organic solvent content are consistent with other findings [16,33].

\subsection{Quantitative analysis}

A four-point quantitation calibration curve was built for each compound by injecting twice the stock solution made with the 9 model compounds in $\mathrm{MeOH} / \mathrm{H}_{2} \mathrm{O}(50 / 50)$ at 5, 10, 30 and $50 \mathrm{ppm}$ each, with the ammonium formate buffer $20 \mathrm{mM} \mathrm{pH} 9$. The peaks' areas were measured on the EIEs. The calibration curves for the LMMOA and the aromatic compounds are shown in Fig. 4(a and b). The values reported in Table 4 are the average of two data points. If the correlation coefficients were acceptable and all above 0.98 for the aromatic compounds, they ranged from 0.92 to 0.98 for the LMMOA due to smaller peak areas (lower sensitivity of the method). It has to be noted that such correlation coefficients cannot fully guarantee a robust quantitative method, but rather aim at a semi-quantitative analysis validation. Generally, linearity over more than three orders of magnitude can be achieved by CE/ESI-MS [35]. As concentrations below $5 \mathrm{ppm}$ were not tested, the limit of detection (LOD) calculated as $3 \mathrm{~S} / \mathrm{N}^{\prime}$ [30] was only roughly estimated with a cut-off value. LOD was found much better for the aromatic compounds (about two to three orders of magnitude below $5 \mathrm{ppm}$ ) than for the LMMOA for which it was close to the $5 \mathrm{ppm}$ cut-off value. Within-day precision $(r)$ was determined on $t_{\mathrm{m}}$ in terms of relative standard deviation (RSD) on 6 injections of the model mixture solution at different concentrations (5-30 ppm), with RSD\% = (standard deviation/average) $\times 100$, and ranged between $1.3 \%$ and $2.4 \%$ (Table 1 ). These values show that the method is slightly less precise than the corresponding CE/UV methods for both types of compounds,

Table 4

Quantitation (calibration curve equations with correlation coefficients $R^{2}$ and percent relative standard deviation values (RSD \%) on the measured peak areas) and sensitivity $\left(\mathrm{S} / \mathrm{N}^{\prime}\right)$ for the model mixture solution.

\begin{tabular}{lllrc}
\hline & Equation & $R^{2}$ & RSD \% & S/N 5 ppm \\
\hline Lactic acid & $y=1256.6 x$ & 0.9837 & 2.23 & 2.9 \\
Glycolic acid & $y=317.2 x$ & 0.9156 & 8.91 & 2.5 \\
Succinic acid & $y=2465.3 x$ & 0.9402 & 6.65 & 5.1 \\
Acetosyringone & $y=16248 x$ & 0.9851 & 0.14 & 56 \\
4-Hydroxyacetophenone & $y=83931 x$ & 0.9926 & 2.55 & 152.9 \\
4-Hydroxybenzaldehyde & $y=72428 x$ & 0.9923 & 13.96 & 150.9 \\
2-Furoic acid & $y=2358.2 x$ & 0.9836 & 0.58 & 6.2 \\
Vanillic acid & $y=12723 x$ & 0.9815 & 5.31 & 29.3 \\
Vanillin & $y=28214 x$ & 0.9881 & 8.76 & 65.7 \\
\hline
\end{tabular}

where repeatability on $t_{\mathrm{m}}$ ranged from $0.16 \%$ to $0.99 \%$. This is hardly surprising since, as it has been reported earlier, in CE/ESI-MS several additional parameters influence the migration of the analytes compared to CE/UV. In particular, the cathode electric contact supplied by the sheath liquid is not as stable and efficient as in normal CE.

\subsection{Application to aged papers}

Fig. 5 shows the base peak electropherograms (BPE) obtained for the three aqueous extract of P3 unaged (a), aged 5 days (b) and aged 14 days (c) analysed with the ammonium formate $20 \mathrm{mM} \mathrm{pH}$ 9 buffer, using the ESI-MS optimised parameters. All the analytes
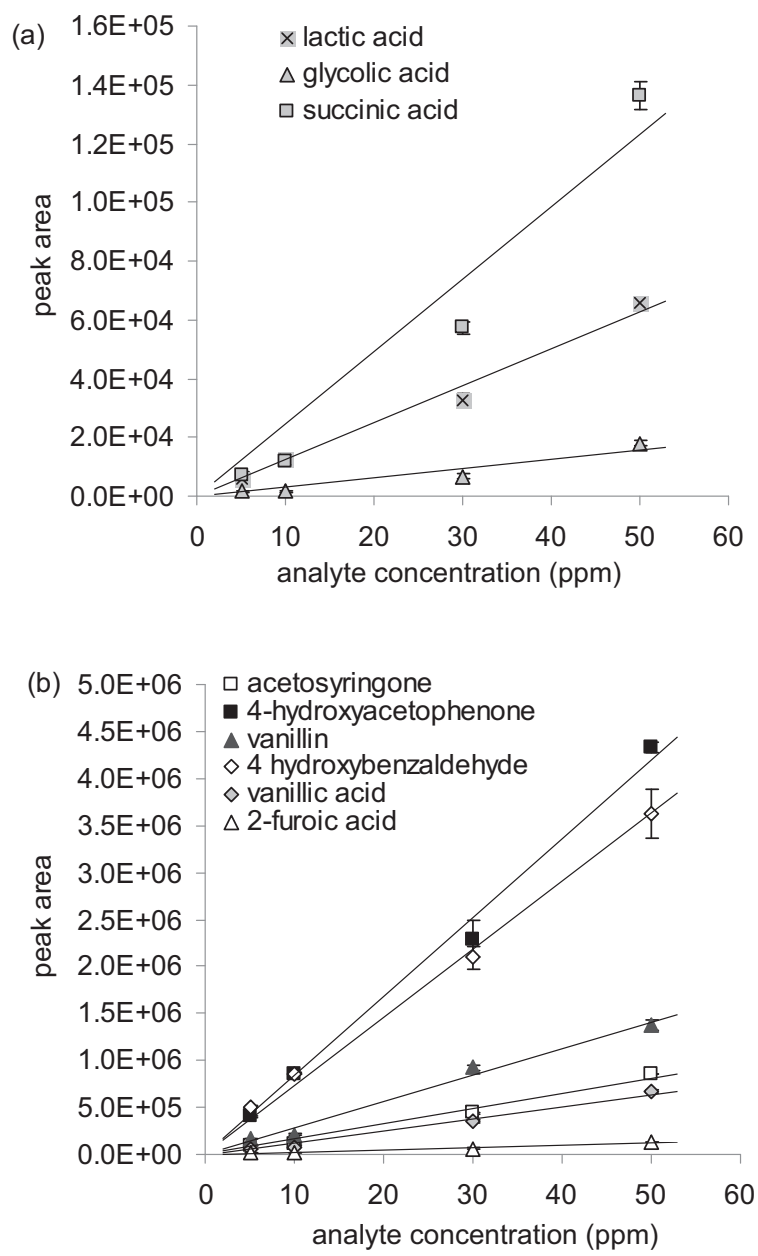

Fig. 4. Calibration curves in ammonium formate $20 \mathrm{mM}$ pH 9 for (a) LMM organic acids and (b) aromatic compounds. 

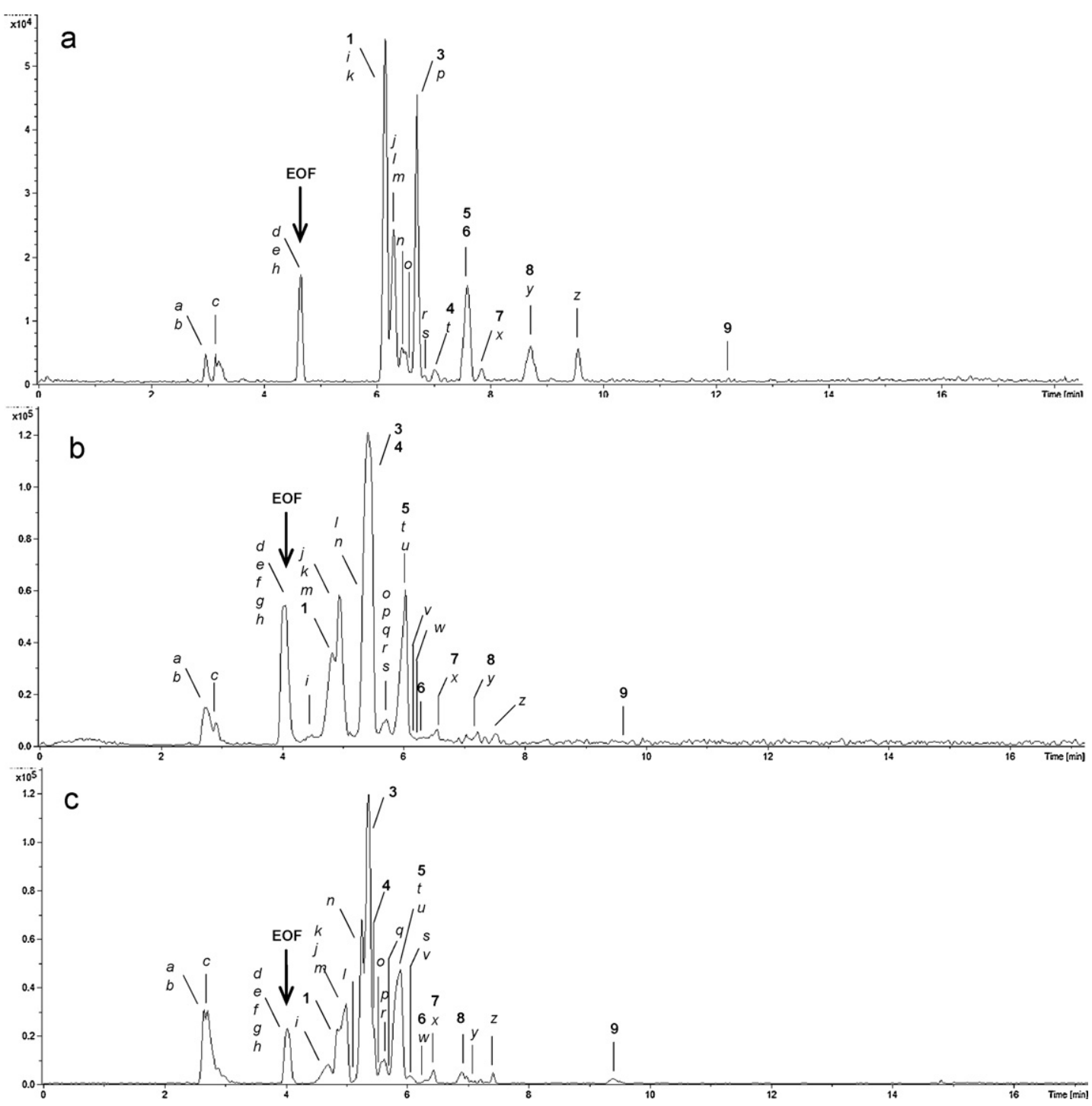

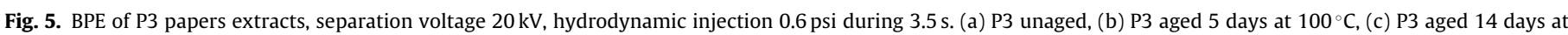

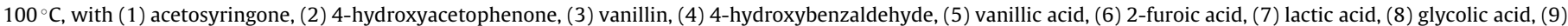
succinic acid, compounds $a$ to $o$ listed in Table S3.

migrated within $13 \mathrm{~min}$. For the unaged sample, $t_{\mathrm{m}}$ were similar as for the model compounds mixture, whereas they were slightly shifted to lower values for the papers aged 5 and 14 days. This could be due to a matrix effect, the quantity of analytes being much higher in aged paper. The quantity of the acids present in the three paper samples extracts were estimated with the calibration curves established previously (Table 5). The results are the average of two values (two injections of each sample). The ageing resulted in a progressive increase in all the peaks, although to not quantifiable values for 2-furoic acid. The LMMOA were equal or below LOQ (estimated as $10 \mathrm{~S} / \mathrm{N}^{\prime}$ ) in the unaged papers but were clearly quantifiable for the aged samples. When possible, the values were compared to the results obtained previously using the CE/UV methods with the exact same papers [1]. It has to be noted that as the papers had been artificially aged at the time of the CE/UV analyses, which were performed 2 years prior to the present analyses, and as paper continues to age, slight differences were expected. Moreover, a high matrix concentration can result in ion suppression problems induced by high molar mass compounds in the matrix, most likely to occur in the most concentrated samples, thereby possibly underestimating the quantitation in the aged papers [16]. Despite these pitfalls which complicate any quantitative analysis in real samples in CE/ESI-MS, the data were found quite comparable: the evolution in the production of some of the degradation compounds in P3 during accelerated ageing is illustrated in Table 6 and Fig. 6a. The amount of glycolic acid was found to increase the most compared to vanillin and vanillic acid in agreement with previous data [1]. Fig. $6 \mathrm{~b}$ shows that the sum of the LMMOA produced was higher than the sum of the aromatic compounds. It has to be noted that formic acid and acetic acid, notoriously produced during paper degradation, which can be identified with $\mathrm{CE} / \mathrm{MS}$, were not included in this work as their molar mass is too low for the MS detection and too close from the detection limit, respectively.

The BPEs of the three samples (Fig. 5) showed several clearly separated additional peaks, which outnumbered the peaks present on the CE/UV electropherograms in our previous study [1] indicating the higher capacity of the method. In most cases the peak areas in the aged samples were larger compared to the unaged sample showing an increased production of the corresponding compounds during ageing and indicating their potential usefulness for degradation state assessment. In the present study a full identification of the unknown compounds could not be carried out but we propose below possible attributions of some of the major peaks based on a literature search (Table S3 in 
Table 5

Quantitation of the compounds found in P3 unaged, aged 5 days, and aged 14 days (average of two runs) as ppm and as $\mu$ moles per gram of paper.

\begin{tabular}{|c|c|c|c|}
\hline & Unaged & Aged 5 days & Aged 14 days \\
\hline \multicolumn{4}{|l|}{ Lactic acid } \\
\hline ppm & $\approx \mathrm{LOQ}$ & $49 \pm 1$ & $51 \pm 15$ \\
\hline$\mu \mathrm{molg}^{-1}$ paper & - & $2.4 \pm 0.1$ & $2.5 \pm 0.7$ \\
\hline \multicolumn{4}{|l|}{ Glycolic acid } \\
\hline ppm & $<\mathrm{LOQ}$ & $36 \pm 1$ & $52 \pm 12$ \\
\hline$\mu \mathrm{mol} \mathrm{g}^{-1}$ paper & - & $2.1 \pm 0.1$ & $3.1 \pm 0.7$ \\
\hline \multicolumn{4}{|l|}{ Succinic acid } \\
\hline ppm & $<$ LOD & $10.9 \pm 0.5$ & $17 \pm 7$ \\
\hline$\mu \mathrm{molg}^{-1}$ paper & - & $0.41 \pm 0.02$ & $0.6 \pm 0.3$ \\
\hline \multicolumn{4}{|l|}{ Acetosyringone } \\
\hline $\mathrm{ppm}$ & $5 \pm 1$ & $18.2 \pm 0.7$ & $16 \pm 3$ \\
\hline$\mu \mathrm{mol} \mathrm{g}^{-1}$ paper & $0.11 \pm 0.03$ & $0.41 \pm 0.02$ & $0.37 \pm 0.07$ \\
\hline \multicolumn{4}{|c|}{ 4-Hydroxyacetophenone } \\
\hline ppm & $N^{a}$ & $1.6^{\mathrm{b}}$ & $2.4 \pm 0.7$ \\
\hline$\mu \mathrm{mol} \mathrm{g}^{-1}$ paper & ND & $0.04^{\mathrm{b}}$ & $0.08 \pm 0.02$ \\
\hline \multicolumn{4}{|c|}{ 4-Hydroxybenzaldehyde } \\
\hline ppm & $0.36 \pm 0.07$ & $1.2 \pm 0.3$ & $1.2 \pm 0.2$ \\
\hline$\mu \mathrm{mol} \mathrm{g}^{-1}$ paper & $0.01 \pm 0.002$ & $0.04 \pm 0.01$ & $0.05 \pm 0.006$ \\
\hline \multicolumn{4}{|l|}{ 2-Furoic acid } \\
\hline ppm & $<\mathrm{LOD}$ & $\approx$ LOD & $<$ LOQ \\
\hline$\mu \mathrm{mol} \mathrm{g}^{-1}$ paper & - & - & - \\
\hline \multicolumn{4}{|l|}{ Vanillic acid } \\
\hline ppm & $13 \pm 2$ & $38 \pm 4$ & $44 \pm 17$ \\
\hline$\mu \mathrm{mol} \mathrm{g}^{-1}$ paper & $0.34 \pm 0.05$ & $1.0 \pm 0.1$ & $1.2 \pm 0.4$ \\
\hline \multicolumn{4}{|l|}{ Vanillin } \\
\hline ppm & $9 \pm 1$ & $17 \pm 4$ & $26 \pm 5$ \\
\hline$\mu \mathrm{mol} \mathrm{g}^{-1}$ paper & $0.25 \pm 0.04$ & $0.5 \pm 0.1$ & $0.8 \pm 0.2$ \\
\hline
\end{tabular}

a ND: not detected.

b One measurement only.

supplementary material). Three peaks migrating before the EOF, with $\mathrm{m} / z 113$ ( $t_{\mathrm{m}}$ about $\left.2.7 \mathrm{~min}\right), 175$ ( $t_{\mathrm{m}}$ about $2.8 \mathrm{~min}$ ) and 181 ( $t_{\mathrm{m}}$ about $2.7 \mathrm{~min}$ ) were found. The peak with $\mathrm{m} / z 113$ could correspond to 2,3-dihydroxycyclopent-2-en-1-one (reductic acid), as it has been shown to originate from pentoses and hexuronic acids $[36,37]$. The peak with $m / z 175$ could be glucuronolactone, although in alkaline medium, the equilibrium between lactone and the parent straight-chain hydroxy acid is shifted towards the acid form (see peak with $m / z 193$ below). A slower migration of these compounds than the EOF would have been expected but, as explained earlier, modifications in $t_{\mathrm{m}}$ and inversions are possible in complex matrices. Two peaks co-migrating with the $\operatorname{EOF}\left(t_{\mathrm{mEOF}}=4.6,4.0\right.$ and $4.1 \mathrm{~min}$ on the BPEs of Fig. 6a-c, respectively) with $\mathrm{m} / \mathrm{z} 149$ and $\mathrm{m} / z 179$ can be attributed to monosaccharides, which because of their high $\mathrm{p} K_{\mathrm{a}}$ values (above 12), are neutral in the BGE. The peak with $\mathrm{m} / \mathrm{z} 149$ likely corresponds to pentoses (xylose, arabinose), and the peak with $m / z 179$, to hexoses (glucose, mannose, galactose). These sugars have been previously identified in P3 [1] and are known degradation products arising both from hemicelluloses and cellulose degradation [38,39]. A minor component in the EOF peak (for the two aged samples only) with $m / z 177$ could be attributed to hexodialdoses, which can arise from radical oxidation of carbohydrates [40], and which would be expected to happen during the heat/humid ageing of the paper. Besides acetosyringone, two other compounds with $\mathrm{m} / z 195$ were present in the paper extracts.
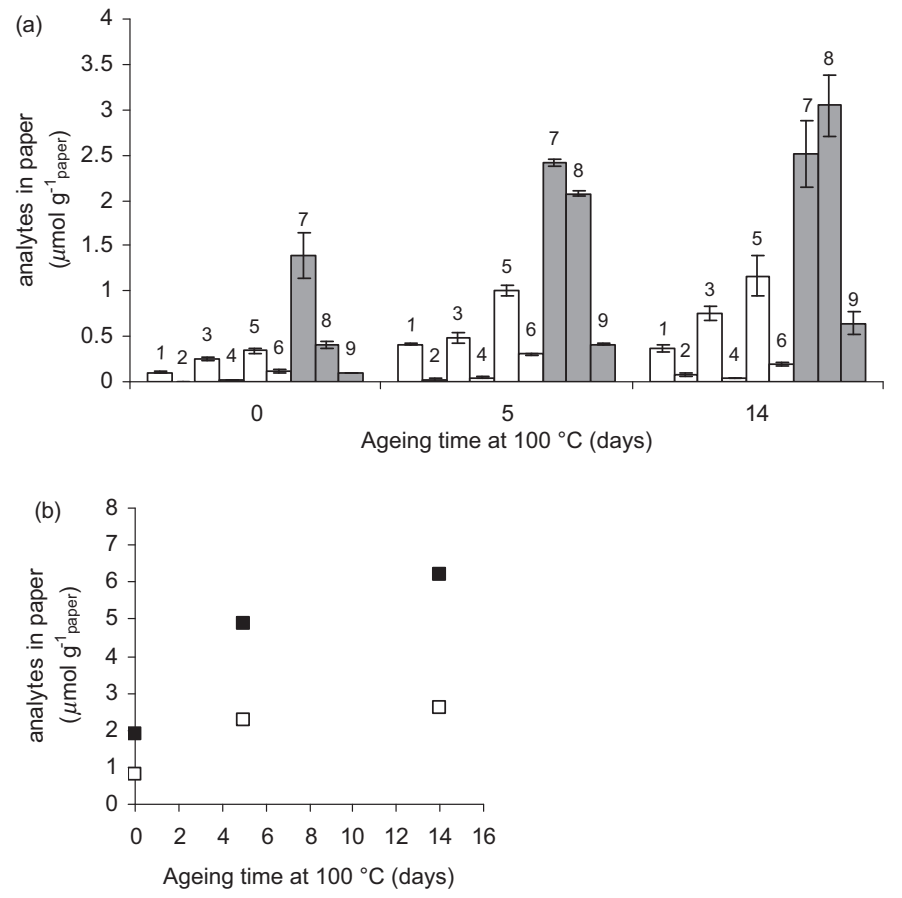

Fig. 6. Quantitation of the analytes ( $\mu \mathrm{molg}^{-1}$ paper) in P3 as a function of ageing time, separation voltage $20 \mathrm{kV}$, hydrodynamic injection $0.6 \mathrm{psi}$ during $3.5 \mathrm{~s}$, electrolyte: ammonium formate $20 \mathrm{mM} \mathrm{pH} 9$. (a) (1) acetosyringone, (2) 4 hydroxyacetophenone, (3) vanillin, (4) 4-hydroxybenzaldehyde, (5) vanillic acid (6) 2-furoic acid, (7) lactic acid, (8) glycolic acid, (9) succinic acid. (b). (ם) Sum of the LMMOA, $(\square)$ sum of the aromatic compounds.

One co-migrated with the EOF, and no possible attribution was found. The other one was negatively charged ( $t_{\mathrm{m}}$ about $\left.7.5 \mathrm{~min}\right)$, and could possibly be attributed to gluconic acid $\left(\mathrm{p} K_{\mathrm{a}}=3.86\right)$ as it is a well-know product from glucose and cellulose oxidation, mostly in acidic conditions [41]. The other peak with $m / z 177$, also present on the BPE of the two aged samples only ( $t_{\mathrm{m}}$ about $4.6 \mathrm{~min}$ ), could not be attributed. Other major peaks on the BPE found at higher $t_{\mathrm{m}}$ than the EOF were: $m / z 181\left(t_{\mathrm{m}}\right.$ about $5.0 \mathrm{~min}$ ), possibly 2,3dimethoxybenzoic acid ( $\left.\mathrm{p} K_{\mathrm{a}} 3.97\right)$, as it has been mentioned to being formed from glucose [42]; $\mathrm{m} / z 193$ ( $t_{\mathrm{m}}$ about $5.3 \mathrm{~min}$ ), which could correspond to glucuronic acid $\left(\mathrm{p} K_{\mathrm{a}} 2.93\right)$ or 2-ketogluconic acid $\left(\mathrm{p} K_{\mathrm{a}}=2.66\right) ; \mathrm{m} / z 211$ ( $t_{\mathrm{m}}$ about $\left.5.0 \mathrm{~min}\right)$, for which no compound could be proposed; $m / z 149\left(t_{\mathrm{m}}\right.$ about $\left.5.7 \mathrm{~min}\right)$, possibly tartaric acid, and $m / z 119\left(t_{\mathrm{m}}\right.$ about $\left.6.0 \mathrm{~min}\right)$, possibly tartronic acid. The three later compounds have been found as oxidation products originating from the ozonation of glucose in acidic conditions [41]. A series of additional minor peaks are also proposed (peak area are not reported in Table $\mathrm{S3}$, supplementary material), the attributions of which were mostly made among C3 to C6 hydroxy acids (glucaric, arabinoic, ketoglucaric, malic, erythronic, glyceric) [41]. All these attributions remain of course prospective at this stage of the research and in the next phase of the study MS/MS will have to be performed for confirmation.

Table 6

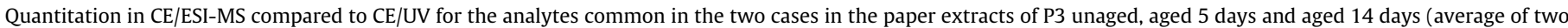
runs) ( $\mu \mathrm{mol} \mathrm{g}^{-1}$ paper $)$.

\begin{tabular}{|c|c|c|c|c|c|c|}
\hline & \multicolumn{2}{|l|}{ P3-UA } & \multicolumn{2}{|l|}{ P3-A5d } & \multicolumn{2}{|l|}{ P3-A14d } \\
\hline & CE/ESI-MS & CE/UV & CE/ESI-MS & CE/UV & CE/ESI-MS & CE/UV \\
\hline Glycolic acid & - & $0.46 \pm 0.03$ & $2.07 \pm 0.06$ & $1.23 \pm 0.06$ & $3.1 \pm 0.7$ & $2.33 \pm 0.06$ \\
\hline 2-Furoic acid & $0.12 \pm 0.03$ & $0.16 \pm 0.008$ & $0.30 \pm 0.03$ & $0.28 \pm 0.005$ & $0.20 \pm 0.05$ & $0.32 \pm 0.004$ \\
\hline Vanillic acid & $0.34 \pm 0.05$ & $0.52 \pm 0.01$ & $1.0 \pm 0.1$ & $0.47 \pm 0.01$ & $1.2 \pm 0.4$ & $0.78 \pm 0.02$ \\
\hline Vanillin & $0.25 \pm 0.04$ & $0.34 \pm 0.03$ & $0.5 \pm 0.1$ & $0.42 \pm 0.07$ & $0.8 \pm 0.2$ & $0.79 \pm 0.01$ \\
\hline
\end{tabular}




\section{Conclusion}

Heritage conservation science is a field of research which covers several transversal disciplines, both in science and humanities, such as chemistry, physics, materials science, biology, art history and archaeology. The problems this field has to tackle with are complex, partly due to the composite nature of the artefacts, their art and culture calling, and the ethics related to our responsibility in their preservation. The techniques used and methods developed for the analysis of cultural heritage artefacts thus need to be highly sensitive, selective and abide to certain requirements, one of which is small sample size. CE/ESI-MS fulfills all these requirements. In this work, CE/ESI-MS was applied to the study of degradation compounds from paper. The method developed with standard compounds was fully optimised using designs of experiment, and a first trial of application to real samples prepared from ligneous paper that had undergone artificial ageing proved successful. These samples formed a complex matrix as besides the degradation byproducts formed during ageing, the paper also contained sizing and fillers. The 9 analytes of interest, LMMOA and aromatic compounds (lignin derivatives), could be separated within $13 \mathrm{~min}$, identified and for most of them quantified. It is noteworthy that these degradation products were among two families of compounds which had not been analysed simultaneously to date. Furthermore, the multiplicity of peaks showed a very complex composition of the samples, and the knowledge of the $m / z$ value and migration time allowed proposing possible peak attributions for those which intensity increased during ageing. For instance a series of hydroxy acids such as glucuronic acid (and glucuronolactone), and gluconic acid, as well as several monosaccharides, both pentoses and hexoses are expected in lignocellulosic papers and were likely present. Future work will include the use of MS/MS to certify their nature. In order to perfect a comprehensive analysis of paper degradation products using CE/ESI-MS, the determination and quantification of monoand oligosaccharides in complex paper matrices using higher $\mathrm{pH}$ buffers is the next step in this research.

\section{Appendix A. Supplementary data}

Supplementary data associated with this article can be found, in the online version, at doi:10.1016/j.talanta.2011.12.032.

\section{References}

[1] A.-L. Dupont, C. Egasse, A. Morin, F. Vasseur, Carbohydr. Polym. 68 (2007) 1-16.

[2] G. Buchbauer, L. Jirovetz, M. Wasicky, A. Nikiforov, J. Pulp Pap. Sci. 21 (1995) 398-400.

[3] O. Dahlman, A. Jacobs, A. Liljenberg, A.I. Olsson, J. Chromatogr. A 891 (2000) 157-174.

[4] T.P. Nevell, in: T.P. Nevell, S.H. Zeronian (Eds.), Ellis Horwood Series Chemical Science, Cellulose Chemistry and its Applications, John Wiley \& Sons, 1985, pp. 243-265.
[5] E.J. Parks, C.M. Guttman, K.L. Jewett, F.E. Brinckman, Report NISTIR 4456, National Institute of Standards and Technology, Gaithersburg, MD, 1990.

[6] C.J. Shahani, G. Harrison, in: V. Daniels, A. Donithorne, P. Smith (Eds.), IIC Congress: Works of Art on Paper, Books, Documents and Photographs, Techniques and Conservation, International Institute for Conservation, London, 2002, pp. 189-192.

[7] A. von Brocke, G. Nicholson, E. Bayer, Electrophoresis 22 (2001) 1251-1266.

[8] P. Schmitt-Kopplin, M. Frommberger, Electrophoresis 24 (2003) 3837-3867.

[9] C.W. Klampfl, Electrophoresis 27 (2006) 3-34.

[10] W.F. Smyth, P. Brooks, Electrophoresis 25 (2004) 1413-1446.

[11] E.J. Maxwell, D.D.Y. Chen, Anal. Chim. Acta 627 (2008) 25-33.

[12] P.L. Bégin, E. Kaminska, Restaurator 23 (2002) 89-105.

[13] T. Sawoszczuk, A. Barański, J.M. Łagan, T. Łojewski, K. Zięba, J. Cult. Herit. 9 (2008) 401-411.

[14] T. Łojewski, K. Zięba, A. Knapik, J. Bagniuk, A. Lubańska, J. Łojewska, Appl. Phys. A 100 (2010) 809-821.

[15] M. Mokkadem, P. Gareil, J.-E. Belgaied, A. Varenne, Electrophoresis 29 (2008) 1957-1964.

[16] D. van Pinxteren, H. Herrmann, J. Chromatogr. A 1171 (2007) 112-123.

[17] Y. Iinuma, H. Herrmann, J. Chromatogr. A 1018 (2003) 105-115.

[18] A.M. Gómez-Caravaca, V. Verardo, A. Segura-Carretero, M.F. Caboni, A. Fernández-Gutiérrez, J. Chromatogr. A 1209 (2008) 238-245.

[19] A. Carrasco-Pancorbo, D. Arráez-Román, A. Segura-Carretero, A. FernándezGutiérrez, Electrophoresis 27 (2006) 2182-2196.

[20] J.J. Berzas Nevado, G. Castañeda Peñalvo, V. Rodríguez Robledo, G. Vargas Martínez, Talanta 79 (2009) 1238-1246.

[21] T. Soga, Y. Ueno, H. Naraoka, Y. Ohashi, M. Tomita, T. Nishioka, Anal. Chem. 74 (2002) 2233-2239.

[22] K. Harada, E. Fukusaki, A. Kobayashi, J. Biosci. Bioeng. 101 (5) (2006) 403-409.

[23] H. Sawada, C. Nogami, Anal. Chim. Acta 507 (2004) 191-198.

[24] S.K. Johnson, L.L. Houk, D.C. Johnson, R.S. Houk, Anal. Chim. Acta 389 (1999) $1-8$.

[25] C.W. Klampfl, W. Buchberger, P.R. Haddad, J. Chromatogr. A 881 (2000) 357-364.

[26] J. Ding, P. Vouros, Anal. Chem. News Features (1999) 378A-385A.

[27] A. Bogolitsyna, M. Becker, A.-L. Dupont, A. Borgards, T. Rosenau, A. Potthast, J. Chromatogr. A 1218 (2011) 8561-8566, doi:10.1016/j.chroma.2011.09.063.

[28] J. Hagberg, J. Chromatogr. A 988 (2003) 127-133.

[29] J.R. Catai, J. Sastre Toraño, G.J. de Jong, G.W. Somsen, Electrophoresis 27 (2006) 2091-2099.

[30] L.R. Snyder, J.J. Kikland, J.L. Glajch (Eds.), Practical HPLC Method Development, 2nd ed., John Wiley \& Sons, 1997, p. 22.

[31] T.M. Annesley, Clin. Chem. (Washington, DC, U.S.) 49 (7) (2003) 1041-1044.

[32] L.L. Jessome, D.A. Volmer, LCGC North Am. 24 (5) (2006) 498-510.

[33] K. Huikko, T. Kotiaho, R. Kostiainen, Rapid Commun. Mass Spectrom. 16 (2002) $1562-1568$.

[34] J. Zheng, M.W. Jann, Y.Y. Hon, S.A. Shamsi, Electrophoresis 25 (2004) 2033-2043.

[35] J. Ohnesorge, C. Neusüß, H. Wätzig, Electrophoresis 26 (2005) 3973-3987.

[36] T. Popoff, O. Theander, Carbohydr. Res. 22 (1972) 135-149.

[37] T. Ahmad, R. Andersson, K. Olsson, E. Westerlund, Carbohydr. Res. 247 (1993) 217-222.

[38] F. Shafizadeh, in: T.P. Nevell, S.H.Zeronian (Eds.), Ellis Horwood Series Chemical Science, Cellulose Chemistry and its Applications, John Wiley \& Sons, 1985, p. 282.

[39] Y.-Z. Lai, in: D.N.S. Hon, N. Shiraishi (Eds.), Wood and Cellulosic Chemistry, 3rd ed., Marcel Dekker Inc., 2001, p. 451.

[40] M. Carlsson, The inter- and intramolecular selectivity of the carbonate radical anion in its reactions with lignin and carbohydrates, Doctoral Thesis, 2005, p. 40.

[41] O. Marcq, J.-M. Barbe, A. Trichet, R. Guilard, Carbohydr. Res. 344 (2009) 1303-1310.

[42] T. Popoff, O. Theander, Anal. Chem. Scand. B30 (1976) 397-402. 